\title{
CONCEPT MAPPING MODEL, ACADEMIC DISCIPLINES AND INTERDISCIPLINARITY
}

\author{
Steven McAlpine (USA)
}

\begin{abstract}
Why do we use maps? What sense of understanding does a map provide that a simple list of directions cannot? Beginning with an examination of the most useful properties of maps, we will then review a methodology for constructing a conceptual map used to explore the complexities of a topic or problem.
\end{abstract}

KEYWORDS: Concept mapping, map model, Napoleon's Russian Campaign, interdisciplinary research

We use maps to avoid getting lost; at least that is our hope. However, if the map doesn't have sufficient detail, we may have to stop to ask for directions. How many times have we received a long set of verbal instructions through our car window, hoping that we will remember distances, landmarks, left and right turns?

What a well designed map provides is a visual sense of orientation, a non- linear understanding of where we are and where we are doing. Consider the map on the figure 1 .

If we are at point "A" in Baltimore, and we want to make it to class on time at the University of Maryland Baltimore County (UMBC) in rush hour traffic, we can consider our options: Head west on Wilkens Avenue? Join everyone else on I-95 and I-695? If we decide to take the bus, or the train, then we need a different map. So before we can decide which map we need, we must be very clear about the purpose of our journey. Where and when are we going? What is the best means of transportation? Do we want the quickest route? The safest Route? The scenic route? The least expensive route? The route with the smallest carbon footprint? What if we wanted the healthiest route? Is there a map of biking lanes and trails? Even more perplexing is the reality that we often want to satisfy more than one need for successfully completing our journey; ideally, the fastest route would also be the least expensive. Does the map above help us to assess these competing priorities, to balance or connect our main concerns? If not, how might we design a map that does?

Once we begin to ask more of a map (or an academic discipline) than its frame allows, we need to move to a more conceptual approach. To draw from the example on the figure 1, the map cannot show us which routes are most congested (although Google Traffic now does), which routes have the lowest frequency 
of accidents, which are most aesthetically pleasing, or if any corresponding bus/ train/bike routes exist.

\section{Figure 1: Map of Maryland Baltimore County}

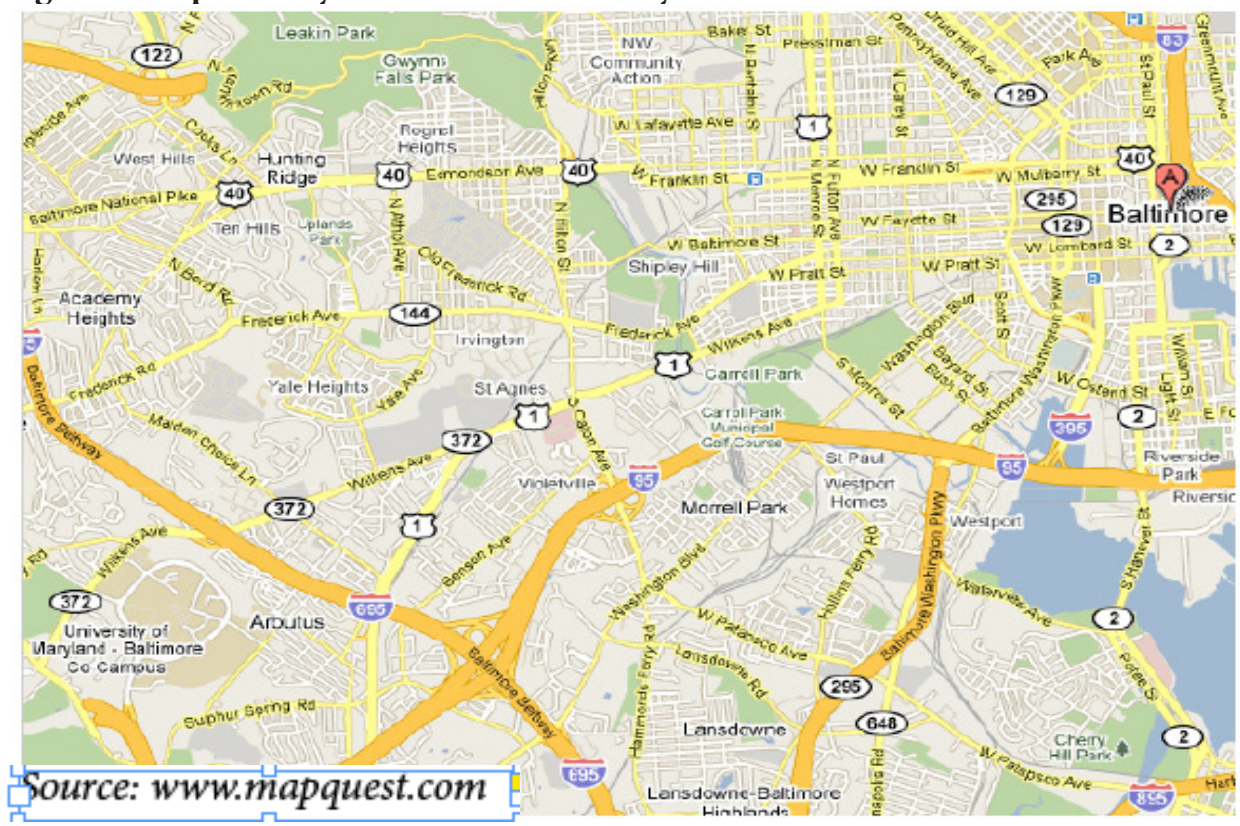

As we consider alternate approaches to mapping a journey from Point A to Point $\mathrm{B}$, let us turn to the map on the figure 2 of Napoleon's march on Moscow during the War of 1812 by French engineer Charles Joseph Minard ( translated; a larger version is available online at http://www.math.yorku.ca/SCS/Gallery/minard/minard-odt.jpg).

On June 24, 1812, Napoleon's army of 422,00 men (some historians estimate that the size of the Grand Armee was as high as 690,000), the largest army assembled up to that point in European history, crossed the river Neman and marched east towards Moscow. On September 14, 1812, Napoleon reached Moscow, which had been abandoned and stripped of the supplies that Napoleon's men needed most at this point - especially food. The map visually depicts the direction in which the army moved, its size, major river crossings and cities, the timeline of the invasion and retreat, but most importantly, the temperature at key dates and locations during Napoleon's retreat during the onset of winter.

The tragic story told by this map is not the shedding of blood, nor some victorious counterassault by the Russian army, but the power of Napoleon's worst enemy: the extremely cold weather during the fall and winter of 1812, where temperatures dropped as low as 34 degrees below zero. The final number on the map tells us that only 10,000 men lived to cross the Neman River to return home. The highest estimate by historians is that perhaps 40,000 soldiers - less than ten percent of the original army - survived the campaign.

A key quality of effective maps is the visualization of key connections between perspectives. In Minard's map, we see the connection between geography, temperature, and mortality (a striking aspect of the map is the rapidly thinning 
line, representing the number of soldiers, on Napoleon's retreat). In the map of Baltimore on the figure 1, we see literal road connections between downtown Baltimore and the UMBC campus, as well as distance and direction.

Figure 2: Map of Napoleon's Russian Campaign (1812-1913) Produced by Minard

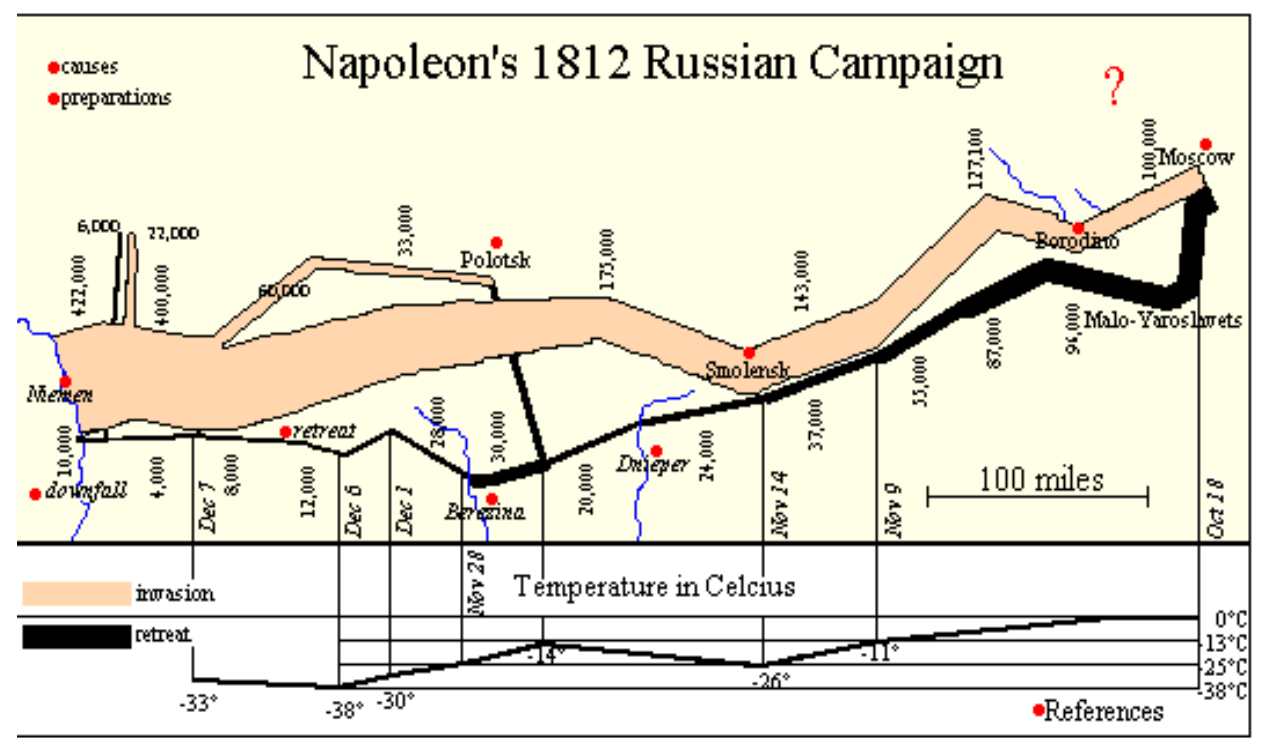

Source: http://www.math.yorku.ca/SCS/Gallery/minard/minard-odt.jpg

Note: This graphic has been translated from French to English and modified to most effectively display the temperature data.

But how might we map the conceptual space in which we are grappling with a complex problem? The complexity of the problem may require connections between concepts from a variety of professional fields and academic disciplines. To use an analogy for a mapping framework, imagine a wheel with the complex problem at its center, or "hub":

Figure 3: Mapping Framework with the Complex Problem
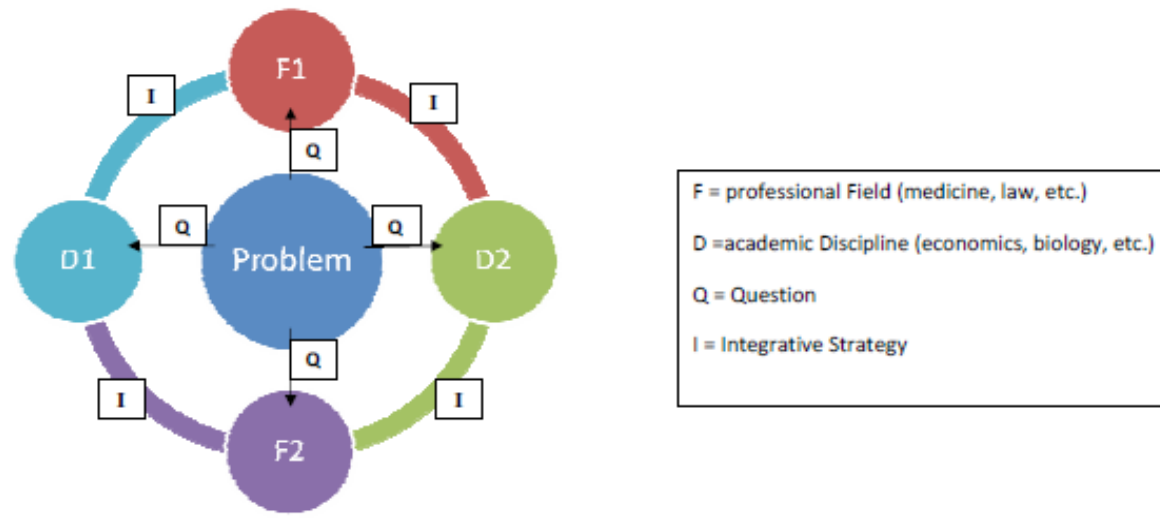

Any complex problem - such as how to provide services to elders who decide to "age in place" (i.e. remain in their homes and use variety of services such as 


\section{Crossing the Border: International Journal of Interdisciplinary Studies}

visiting nurses) - will invite a related set of questions and challenges. Questions such as "who will pay for these services?" raise economic issues. Each discipline, such as economics, offers tools with which to address these questions: concepts such as opportunity cost or methods such cost - benefit analysis. In the field of medicine, a method such as differential diagnosis might be a valuable tool for understanding the root cause of physical symptoms such as high fever or acute pain.

However, these disciplinary and professional perspectives do not exist in isolation. The outer rim of the wheel connects these perspectives in a variety of ways. There are three models of integration (Repko 2008) and five bridging strategies (miller and Boix Mansilla 2004) that describe how disciplines and fields interact with one another, i.e. what is happening at the interface between perspectives. For example, the American health care system finds itself in a conflict between ethical clues (for example, do all citizens of a country - whether it be Canada or the United States - have a right to receive health care? Is it ethical to offer health care only to those who can afford it ?) and economic realities (how will we fund a system that provides adequate health care for all Americans?). We call this negotiation between disciplinary perspectives "advancing through checks and balances" (Miller and Boix Mansilla 2004).

The actual map can often look more complex than the model on the figure 3. Consider the concept map on the figure 4, designed by UMBC student Donna Viola for an interdisciplinary studies assignment in which students were asked, "what is the relationship between food production/consumption and energy production/consumption in the United States?" The solid lines indicate connections to academic disciplines or professional fields; the dotted lines indicate interdisciplinary connections driven by key questions.

\section{Figure 4: Relationship between Food and Energy Production/Consumption}

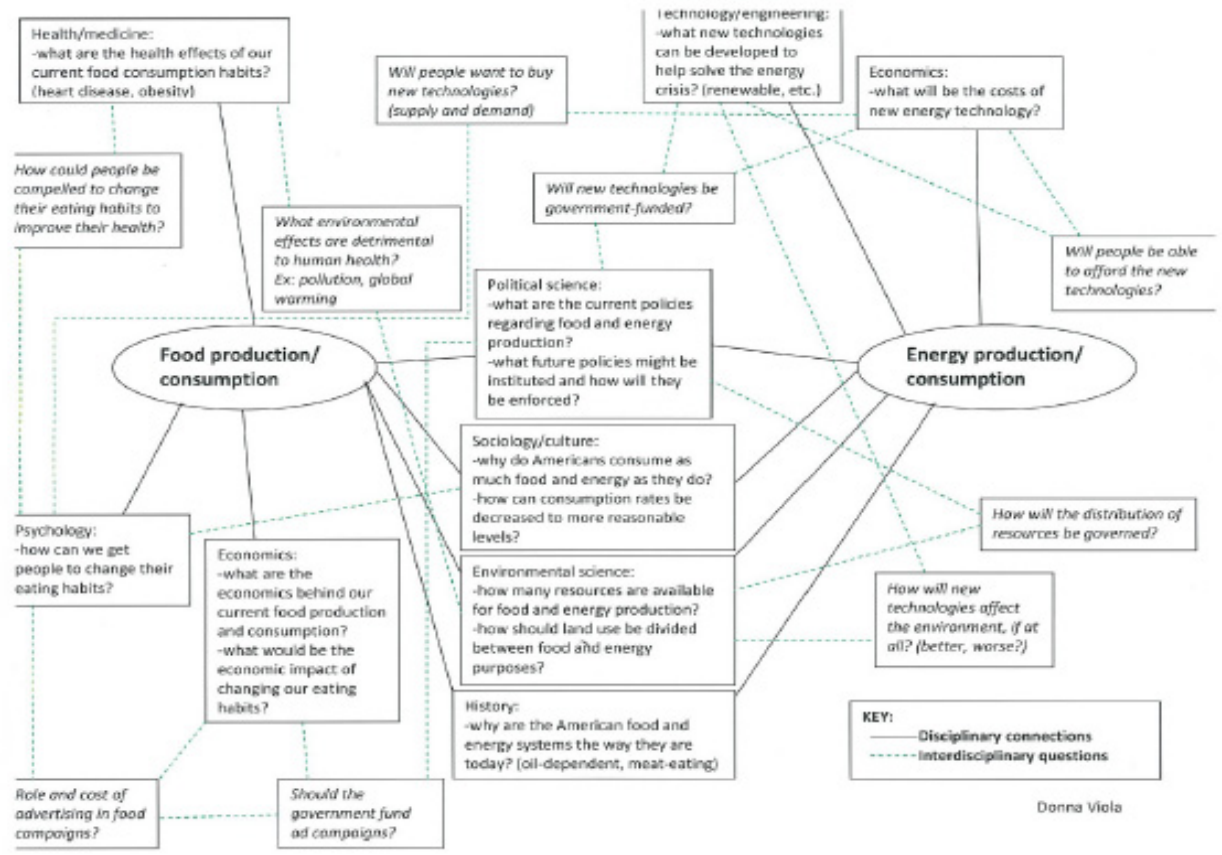


How does this method of concept mapping help us to understand the problem or complex topic at hand? First, it is important to remember that the problems we face are part of a larger system, or stand at the interface of two or more system (as in the case of the food/energy map). The concept map allows us to see the problem space in a way that makes visible connections between different perspectives, and to deploy a variety of bridging strategies ${ }^{i}$ or models of integration ${ }^{i i}$ that may contribute to an integrative and innovative solution to the problem. Second, mapping allows us to explore a complex issue in a non-liner way: As we ask key questions from the perspective of one discipline, we realize that other disciplines may also have relevant concepts or theories to help answer the question. There is no single "route" to exploring complex issues. Third, mapping allows us to refine our research questions and our perspective on the problem as we proceed. We may discover that what we were researching is a symptom rather than a root cause, or that our initial research question is too broad. For example, in a recent discussion on the future of America's energy policy, it became apparent that many of the strategies proposed by the American Clean Energy and Security Act of 2009 do not address the root problem: being more efficient with the use (and capture of) the variety of energy sources readily available to us. It was noted in class that at University Maryland Baltimore County, an Honors University known for its science and engineering programs, there is not a single solar panel or wind turbine in place.

To focus more on an integrative analysis of a system, consider the map on the figure 5. Although the methodology is somewhat different (instead of posing

Figure 5: Concept Map o Energy Policy Summit Meeting, INDC 330 April 15th, 2010

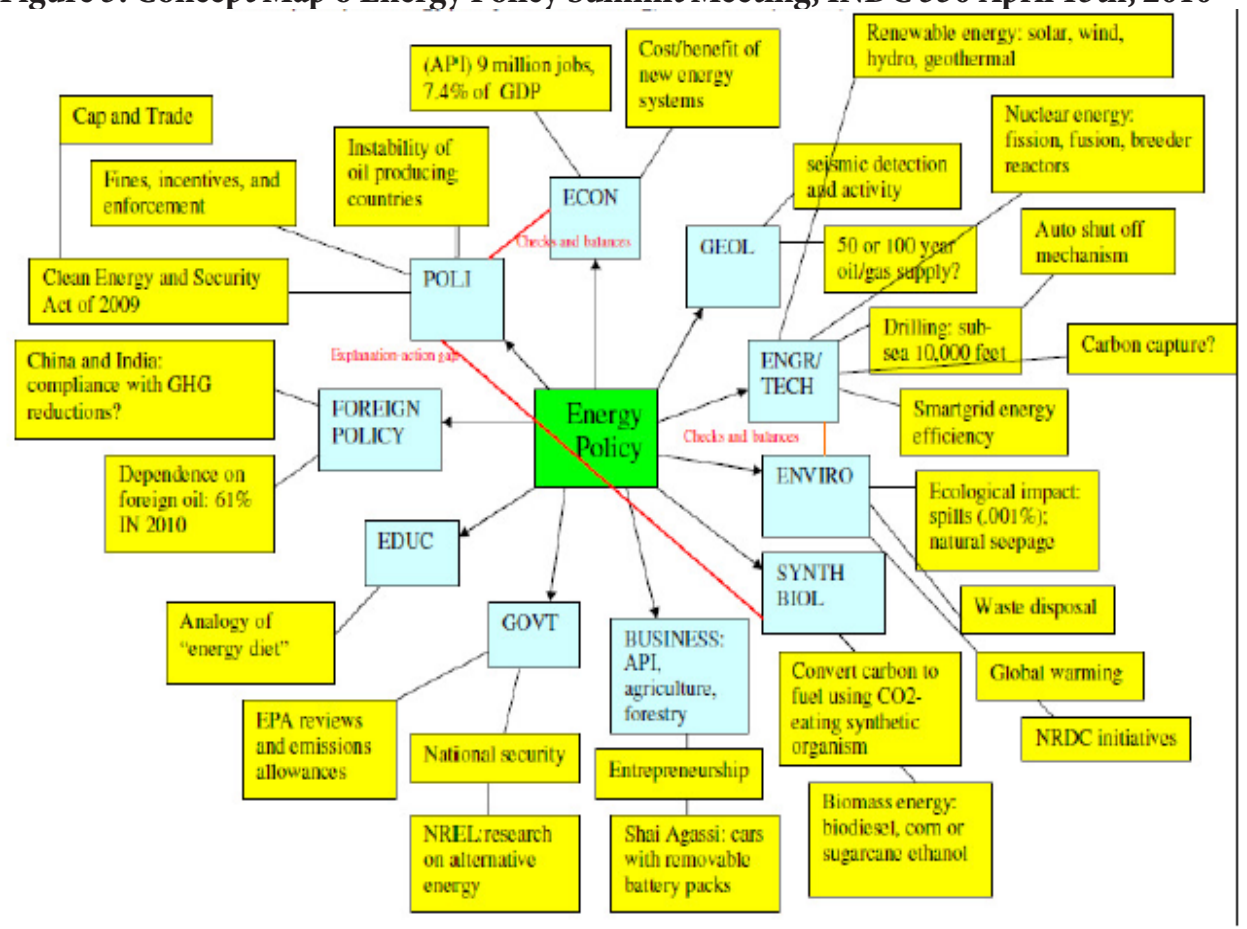




\section{CONCEPT MAPPING SOFTWARE}

Questions for each discipline, key concepts and issues are identified), there are clearly some important integrative strategies to consider:

1. (Checks and balances) We need to consider the environmental impact of new technologies that we create.

2. (Checks and balances) We need to consider the economic impact of the new policies we create.

3. (Bridging the explanation-action gap) Following on \#2, if we create a new policy for "carbon capture" for example, we must create an action strategy that would help to solve the problem that we can explain. In this case, policymakers and scientists agree that we must reduce carbon emissions (or the excess amount of $\mathrm{CO} 2$ in the atmosphere). The explanation then is to create policies that call for carbon capture. But how? What do we do with that excess carbon? Dr. Craig Venter is working on an action plan using synthetic biology to create a $\mathrm{CO} 2$-eating organism that would produce fuel that could be used in the existing biodiesel fuel system.

Although the concept mapping model on the figure 3 and the concept maps on the figures 4 and 5 were done in Microsoft Word, there are concept mapping programs that are specifically designed "scaffold' the process:

- C-Map tools htt://cmap. ihmc.us/conceptmap.html

- Mindjet http://www.mindjet.com/

\section{RECOMMENDED READING}

Edward Tufte is an expert in the presentation of informational graphics and the author of a variety of books on information design and visual literacy, including The Visual Display of Quantitative Information (1983), Envisioning Information (1990), Visual Explanations: Images and Quantities, Evidence and Narrative (1997), and most recently, Beautiful Evidence (2006).

\section{NOTES}

i. Miller \&Boix Mansilla. (2004). Thinking Across Perspectives and Disciplines. Cambridge, MA: Harvard Project Zero.

ii. Repko, Allen. (2008). Interdisciplinary Research: Process and Theory. Thousand Oaks, CA: Sage Publishing.

\section{ABOUT THE AUTHOR}

Steven McAlpine is an Assistant Director who joined the Interdisciplinary Studies (INDS) team in June of 2006 as a Program Advisor and Instructor for the Capstone Seminar (INDS 480). Before coming to the University Maryland Baltimore County (UMBC), USA, he worked as a researcher and seminar facilitator for the Interdisciplinary Studies Project at Harvard Project Zero. While at Harvard, he designed a Teachers Guide for Walden Media's IMAX film "PULSE: a STOMP Odyssey" and worked as an education consultant for the Boston Arts Academy. Email: mcalpine@ umbc.edu 